\title{
The outbreak of Rheumatic Fever in the city of Trieste
}

\section{A De Cunto*, P Salierno, I L'Erario, F Verzegnassi, N Giurici and L Lepore}

\author{
Address: IRCCS Burlo Garofolo, Trieste, Italy \\ * Corresponding author
}

\author{
from $15^{\text {th }}$ Paediatric Rheumatology European Society (PreS) Congress \\ London, UK. 14-17 September 2008 \\ Published: 15 September 2008 \\ Pediatric Rheumatology 2008, 6(SuppI I):PI3 I doi:I0.I |86/I546-0096-6-SI-PI3 I
}

This abstract is available from: http://www.ped-rheum.com/content/6/SI/PI3 I

(c) 2008 De Cunto et al; licensee BioMed Central Ltd.

The annual incidence of rheumatic fever (RF) in developed countries is $0.5-1 / 100.000$ among subjects at risk. The decline in the incidence of RF observed in the past decades was mostly attributed to improvement of the living conditions and the availability of medical care and widespread use of antibiotics. However, focal outbreaks were reported in the past, probably due to resurgence of rheumatogenic strains.

We described the series of RF diagnosed in the city of Trieste between April 2007 and April 2008. 10 cases of acute $\mathrm{RF}$ were reported, 7 females and 3 males. The median age was 6.11 years ( $4.6-10$ years). $7 / 10$ of patients had a history of recent upper respiratory tract infection, 3/10 received oral amoxicilline. Migratory polyarthritis occurred in $50 \%$ of patients; carditis in $60 \%$ (in 2 of 10 valvular regurgitation was demonstrated by echocardiography without accompanying ausculatory evidence). Chorea occurred in $30 \%$ of patients. No patient presented erythema marginatum or subcutaneous nodules. All patients with chorea received corticosteroids with prompt resolution of symptoms except one who responded to valproate and IGIV.

The annual incidence of rheumatic fever in the past ten years in our region was 4-6/100000 per year. We reported the RF outbreak that occurred in the last year in Trieste (43/100.000 population), the capital of the Friuli Venezia Giulia region. This resurgence was focal and not countrywide.
We observed a relatively low incidence of arthritis and high incidence of corea, probably due to a particular rheumatogenic strain that we were unable to identify so far. 